\title{
Erratum: Re-establishing immunological self-tolerance in autoimmune disease
}

Shimon Sakaguchi, Fiona Powrie \& Richard M Ransohoff

Nat. Med. 18, 54-58 (2012); published online 6 January 2012; corrected after print 5 April 2012

In the version of this article initially published, the affiliation of one author (R.M.R.) was incorrectly listed. The correct affiliation is Lerner Research Institute and Mellen Center for Multiple Sclerosis Treatment and Research (Neurological Institute). The error has been corrected in the HTML and PDF versions of the article.

\section{Corrigendum: Epigenetic modulation of the renal $\beta$-adrenergic-WNK4 pathway in salt-sensitive hypertension}

ShengYu Mu, Tatsuo Shimosawa, Sayoko Ogura, Hong Wang, Yuzaburo Uetake, Fumiko Kawakami-Mori, Takeshi Marumo, Yutaka Yatomi, David S Geller, Hirotoshi Tanaka \& Toshiro Fujita

Nat. Med. 17, 573-580 (2011); published online 17 April 2011; corrected after print 4 August 2011; corrected after print 5 April 2012

In the version of this article initially published, the image of the actin bands shown in Supplementary Figure $2 \mathrm{~b}$ was mistakenly rotated 180 degrees. The image has been replaced with the bands in their correct orientation, and the densitometry shown for this blot has been recalculated, which does not affect the conclusions. The figure legends for Figure 1e and Supplementary Figure $2 b$ have also been edited to indicate that the same kidney samples were used for the blots in Figure 1b,e and Supplementary Figure 2b and that the actin bands shown for these blots are identical. 